\title{
Animal models of chronic traumatic encephalopathy
}

\begin{abstract}
Repeated head impacts have been suggested to be associated with the development of the neurodegenerative disorder, chronic traumatic encephalopathy (CTE). CTE is characterized by the accumulation of hyperphosphorylated tau within the brain, with accompanying cognitive and behavioral deficits. How a history of repeated head impacts can lead to the later development of CTE is not yet known, and as such appropriate animal models are required. Over the last decade a number of rodent models of repeated mild traumatic brain injury have been developed that are broadly based on traditional traumatic brain injury models, in controlled cortical impact, fluid percussion and weight drop models, with adaptations to allow for better modeling of the mechanical forces associated with concussion.
\end{abstract}

First draft submitted: 22 December 2016; Accepted for publication: 25 January 2017; Published online: 19 May 2017

Keywords: chronic traumatic encephalopathy $\bullet$ controlled cortical impact $\bullet$ fluid percussion

- tau $\bullet$ traumatic brain injury $\bullet$ weight drop

Concussion is defined as a subset of traumatic brain injury (TBI) that is induced by biomechanical forces and results in a complex series of pathophysiological processes affecting the brain [1]. It is typically caused by a direct blow to the head, face, neck or other part of the body with an impulsive force transmitted to the head, resulting in the rapid onset of acute impairment of neurological function that resolves spontaneously [2]. These clinical symptoms may or may not involve loss of consciousness and can also include headache, changes in behavior, amnesia and insomnia [3] .

Recent studies have highlighted a steady increase in sport related concussion hospitalizations, with an average annual increase of $5.4 \%$ in hospitalization rates in Victoria over a 9-year period [4]. Football codes, including rugby, Australian football and soccer accounted for $36 \%$ of concussion related hospitalizations between 2002 and 2011 [4]. An estimated 1.6-3.8 million sport related concussions occur in the USA each year, however this number is believed to be severely under reported, with up to $50 \%$ of concussions going unreported [5].

High levels of public concern regarding concussion, especially within professional sporting circles, have sparked an increased research presence within the past few years. This is due to the recent link associating participation in contact sports, exposure to repeated events of concussion and the later development of dementia-like symptoms in the years following the initial event [6].

\section{Link between repeated concussion \& later neurodegeneration}

Contact sports have long been linked to the later emergence of disturbances in cognitive function [7], with the first such instance noted in boxers in a study from 1928 describing athletes that appeared 'punch-drunk' in nature following repeated blows to the head [8]. The condition was termed dementia pugilistica in 1937 [9], and was considered
Kelly M McAteer ${ }^{1}$, Renee J Turner $^{1}$ \& Frances Corrigan $*, 1$ 'Discipline of Anatomy \& Pathology, Adelaide Medical School, University of Adelaide, Adelaide, Australia *Author for correspondence: frances.corrigan@adelaide.edu.au
Future
Medicine $\mathrm{fS}$ part of 
neuropathologically distinct from other neurodegenerative diseases in a study from 1973 [10]. The link between repeated concussion and later neurodegeneration then returned to the spotlight with reports of distinct neuropathology within former professional American football players (NFL), as well as others exposed to repetitive concussion including wrestlers, soccer players, rugby players and those in the military [11-14]. A key paper by Omalu et al. reported the presence of diffuse $A \beta$ plaques, neurofibrillary tangles (NFTs) and tau-positive neuritic threads in neocortical areas in a former NFL athlete who had a history of cognitive impairment, mood disorder and parkinsonian symptoms before death [11]. The pattern of tau deposition is distinct from other neurodegenerative diseases, with NFTs, thorned astrocytes and dystrophic neurites aggregating in the superficial cortical layers of the brain, particularly at the base of the sulci and surrounding blood vessels [15], with this presentation now known as chronic traumatic encephalopathy (CTE). Additional neuropathological features of CTE include deposits of phosphorylated TDP-43 as reactive neuronal cytoplasmic inclusions, persistent neuroinflammation, evidence of axonal injury particularly within the deep cortex and subcortical white matter, as well as loss of white matter, most evident in the corpus callosum [16]. This is accompanied by gross atrophy, most pronounced in the frontal, temporal and medial lobes [6]. CTE has been classified into four distinct disease stages that result in an increase in both the severity of clinical symptoms of patients and the associated neuropathology (Table 1). It should be noted that the diagnosis of CTE as its own distinct neuropathology is still under scrutiny and the incidence of what is believed to be pure CTE diagnoses is still unknown.

Although diagnosed postmortem, CTE has been linked to two types of clinical presentations, with manifestation of symptoms years, sometimes decades, after the repetitive concussions were sustained [17]. The first type of presentation manifests earlier in life at approximately 40 years of age and involves changes in mood, such patients are usually more aggressive, impulsive, physically and verbally violent and depressed [17]. The second type of presentation manifests at a much older age than the first, at approximately 60 years of age and involves changes in cognition, showing impairments in episodic memory with patients in this category more likely to develop dementia than in the first [17]. Regardless of the type of initial presentation patients will progressively develop symptoms from both groups. In some cases, patients may also develop Parkinsonian-like symptoms including tremors [18].

The underlying mechanisms for how concussion, in particular repeated exposure to concussion, may predispose to later neurodegeneration with its associated accumulation of pathological proteins, particularly phosphorylated tau, is still not understood. The number of injuries required, the intensity of injuries, the impact of concussive versus subconcussive injuries and the effect of other confounding factors such as preexisting medical conditions and substance abuse on the development of CTE are not yet known. Furthermore, biomarkers for the disease to identify at risk individuals have also not yet been developed. Thus, in order to facilitate a better understanding of disease progression, animal models of repetitive TBI are required that replicate key aspects of the clinical situation.

\section{Suggested requirements for an appropriate animal model of repetitive concussion}

A number of criteria have been proposed to allow animal models of concussion to be reflective of the type of injuries seen clinically. Optimally it has been suggested that the head should be struck directly and the impact should occur with high velocity and rapid acceleration of the head, both rotational and angular [19,20]. Striking the head directly causes higher accelerations of shorter durations [21], with biomechanics studies, principally in NFL footballers suggesting that angular acceleration of the head in the coronal plane has the strongest association with concussion due to generation of the greatest amount of shear force. In regard to the force required, the degree of linear acceleration required for a concussive injury is reported to be close to $100 \mathrm{G}$ [22-25], and is similarly regardless of whether it is reported in helmeted NFL players or in unhelmeted athletes [22,23,26], like Australian Rules Football players [25]. In addition, the range for angular acceleration has been reported as 5022-7912 $\mathrm{rad} / \mathrm{s}^{2}[23,24,27,28]$, providing a guideline for the types of forces that should be generated in animal models.

It should be acknowledged that it is difficult to translate rotational acceleration forces reported in humans to animal models, given the differences in brain size. Inertial effect is dependent on brain mass, and this determines the degree of tissue deformation [29]. As such the same forces applied to a smaller brain produce lower strains and less injury [30,31]. Indeed in the rapid nonimpact inertial head injury models that have been developed to date, injury parameters have been scaled, with the rotational acceleration increased $500 \%$ for a $140 \mathrm{~g}$ baboon brain [32] and $630 \%$ for a $90 \mathrm{~g}$ pig brain [33] to induce the same tissue strains that cause axonal injury in humans. This makes it difficult to produce equivalent rotational acceleration in small animals such as rodents with reports that to achieve equivalent tissue strains in the $2 \mathrm{~g}$ rat brain accelerations $>5000 \%$ of that in human TBI would be required to produce similar tissue strains [34]. 


\begin{tabular}{|c|c|c|c|c|c|}
\hline Stage & Clinical Features & $\begin{array}{l}\text { Gross pathological } \\
\text { changes }\end{array}$ & Pattern of tau deposition & $\begin{array}{l}\text { TDP-43 } \\
\text { immunoreactivity }\end{array}$ & Axonal injury \\
\hline I & $\begin{array}{l}\text { Loss of attention } \\
\& \text { concentration, } \\
\text { increased aggression }\end{array}$ & None & $\begin{array}{l}\text { Focal epicenters of } \\
\text { perivascular pTau in the } \\
\text { sulcal depths limited to } \\
\text { the superior \& dorsolateral } \\
\text { frontal cortices }\end{array}$ & None & Minimal \\
\hline II & $\begin{array}{l}\text { Depression, mood } \\
\text { swings, short- } \\
\text { term memory loss, } \\
\text { loss of attention } \\
\& \text { concentration, } \\
\text { aggression }\end{array}$ & $\begin{array}{l}\text { No cerebral atrophy, } \\
\text { mild enlargement of } \\
\text { ventricles }\end{array}$ & $\begin{array}{l}\text { pTau pathology in multiple } \\
\text { discrete foci of the } \\
\text { cortex. Some small NFTs } \\
\text { present in hypothalamus, } \\
\text { hippocampus, thalamus } \\
\text { and SN }\end{array}$ & $\begin{array}{l}\text { Some TDP-43 } \\
\text { immunoreactivity }\end{array}$ & Minimal \\
\hline III & $\begin{array}{l}\text { Memory loss, } \\
\text { executive dysfunction, } \\
\text { explosivity, loss } \\
\text { of attention \& } \\
\text { concentration, } \\
\text { depression, mood } \\
\text { swings, aggression }\end{array}$ & $\begin{array}{l}\text { Mild cerebral atrophy } \\
\text { with dilation of } \\
\text { ventricles, septal } \\
\text { abnormalities, } \\
\text { atrophy of the } \\
\text { mammillary bodies \& } \\
\text { thalamus, thinning of } \\
\text { the corpus callosum }\end{array}$ & $\begin{array}{l}\text { NFTs widespread } \\
\text { throughout the cortex, } \\
\text { hippocampus and } \\
\text { amygdala. NFTs also } \\
\text { observed in olfactory } \\
\text { bulbs, hypothalamus, } \\
\text { mammillary bodies and SN }\end{array}$ & $\begin{array}{l}\text { TDP- } 43 \text { reactive } \\
\text { neurites observed } \\
\text { in cerebral cortex, } \\
\text { medial temporal } \\
\text { lobe \& brainstem }\end{array}$ & $\begin{array}{l}\text { Axonal loss \& } \\
\text { distorted axonal } \\
\text { profiles observed } \\
\text { in subcortical white } \\
\text { matter (frontal \& } \\
\text { temporal cortices) }\end{array}$ \\
\hline IV & $\begin{array}{l}\text { Executive dysfunction, } \\
\text { memory loss, severe } \\
\text { memory loss \& } \\
\text { dementia, profound } \\
\text { loss of attention \& } \\
\text { concentration, aphasia, } \\
\text { explosivity, aggression, } \\
\text { paranoia, depression, } \\
\text { visuospatial difficulties, } \\
\text { suicidal tendencies }\end{array}$ & $\begin{array}{l}\text { Atrophy of the } \\
\text { cerebral cortex } \\
\& \text { white matter, } \\
\text { medial temporal } \\
\text { lobe, thalamus, } \\
\text { hypothalamus } \\
\text { \& mammillary } \\
\text { bodies. Ventricular } \\
\text { enlargement, cavum } \\
\text { septum pellucidum }\end{array}$ & $\begin{array}{l}\text { Severe pTau abnormalities } \\
\text { widespread throughout } \\
\text { cerebellum, diencephalon, } \\
\text { basal ganglia, brainstem \& } \\
\text { spinal cord }\end{array}$ & $\begin{array}{l}\text { Severe TDP-43 } \\
\text { immunoreactivity } \\
\text { in cerebral } \\
\text { cortex, medial } \\
\text { temporal lobe, } \\
\text { diencephalon, } \\
\text { basal ganglia \& } \\
\text { brainstem }\end{array}$ & $\begin{array}{l}\text { Marked axonal loss } \\
\text { in subcortical white } \\
\text { matter tracts with } \\
\text { distorted axonal } \\
\text { profiles }\end{array}$ \\
\hline
\end{tabular}

Instead animal models can aim to replicate the clinical features of concussion, with acute symptoms of concussion clinically encompassing physical signs such as loss of consciousness, somatic symptoms including headache and vertigo, behavioral changes encompassing cognitive impairment, irritability and sleep disturbance [1]. Evidently many of these measures are difficult to measure in animal models where animals are typically anesthetized, although some newer models are moving toward injury in awake animals [35]. Loss of consciousness is typically seen as an increase in time spent to regain righting reflex, with differences reported between sham animals and injured controls even with anesthesia [36-43]. Further advances in the field could be shifting toward more acute behavioral testing (on the same day) and monitoring of sleep patterns to allow a more complete understanding of the acute effects of our current concussive models. In addition, it has been suggested that given that by definition concussion does not cause structural abnormalities on standard neuroimaging [1], similarly animal models should be mild enough so that they do not cause more severe signs of injury such as contusions, edema or hemorrhage $[44,45]$.

In regard to modeling repeated concussive events, the number, severity and timing between injuries also needs to be considered. It has been suggested that the optimal model would involve impacts beginning in adolescence and continuing sporadically over a long period of time [44], a pattern that has not yet been utilized. Currently animal models typically utilize short spacings between impacts ( $24 \mathrm{~h}-7$ days) [35,37,46], in line with evidence of a window of vulnerability following a single concussion, where a subsequent concussion can have greater long-term effects [47]. However it is not known whether in addition multiple concussive and/or subconcussive impacts spaced at greater intervals could also have long-term consequences in our animal models and whether this may now be more relevant clinically given the advancements in requiring 
rest periods before returning to play. It has been suggested that cumulative exposure to trauma, as in the number of years of engaging in contact sport, rather than the number of concussions, is linked to the severity of tau phosphorylation [48], suggesting a key role of subconcussive hits and that CTE is primarily linked to a long history of repeated head impacts rather than a small number of concussive events in a short space of time. Investigation of the number of head impact in collegiate level American football found that players received up to 1444 head impacts in one season with an average of 6.3 impacts per practice and 14.3 impacts per game sustained per player [49]. Evidently the vast majority of these impacts are subconcussive, with reports of concussion rates ranging from 1.86 [50] to 4.46 [51] per 1000 athlete exposures. This suggests an area that needs to be further explored in our current models, with a number of studies now trying to incorporate a larger number of less severe impacts to attempt to model this clinical situation.

A further complicating factor is the difference in life span between rodents and humans and how to accurately replicate the time-course of the disease. There is typically a gap between a history of repeat injury and onset of symptoms, with behavioral symptoms reported at around 40 years of age and cognitive symptoms at 60 , although noticeable tau pathology has been reported in much younger athletes [14,17]. Compared with an average human life span of 80 years, laboratory rodents live about 2-3.5 years (average 3 years) [52]. In most animal models, injury is induced in young adulthood (10-12 weeks) and at most animals are followed up to 1 year post injury ( 15-16 months) [52]. However this only equates to early middle age in humans, with the need for further studies examining up to 18-24 months post injury, to allow a complete examination of the evolution of the neurological changes induced by repeated head impacts. Furthermore modeling of spacing between injuries is complicated by the differing lifespan. Direct calculation comparing the length of adulthood in rodents and humans, leads to the calculation that 11.8 rodent days are roughly equivalent to one human year [53]. However, if this is used as the basis to determine how far apart head impacts should occur, it ignores the evolution of secondary injury factors following an insult that play a role in the effects of a subsequent insult. For instance Shultz et al. utilized a 5 days gap between their insults, as this allowed for complete resolution of the inflammatory response between impacts [41]. This was equated to an event that took roughly two weeks in humans, rather than the approximately 6 months which would be calculated by chronological age of the rodent. It is evident that this is a key difficulty that needs to be taken into account, and acknowledged as a limitation of the current animal models.

Regardless of their limitations animal models of concussion are required to allow us to develop an insight into the long-term effects of repeated head impacts. Animal models of repeated concussion should also be highly reflective of the current descriptions of CTE, leading to progressive cognitive deficits, mood changes and the gradual appearance of key neuropathological features such as NFTs [14,54-55], changes in white matter integrity [56] and sustained neuroinflammation [49]. Many studies have attempted to scale down current models of severe TBI, such as the controlled cortical impact (CCI) and fluid percussion (FP) injuries and weight drop models, with modifications to replicate key features seen clinically.

\section{Current animal models of repeated concussion}

\section{Controlled cortical impact}

A popular model of injury used currently in the development of repetitive mild TBI (mTBI) animal models is a modified version of the CCI model of TBI. Classically, CCI involves the use of a rigid impactor to deliver mechanical energy to the dura of the brain, exposed via a craniotomy to an animal restrained in a stereotaxic device to produce a focal contusive injury [57]. To replicate a concussive injury the model has typically been adapted to negate the need for a craniotomy, with use of rubber or silicone tips to allow impact to the skull directly [36,43,58-60] or to a form fitting steel cap [35,61], without generating an overt focal necrotic lesion. This is important as secondary impacts are delivered in the same location as the first, which would be confounded by the presence of a contusive injury. Indeed, the only report of significant cerebral hemorrhage and extensive cortical tissue loss in a CCI model of rmTBI was when direct impact to the dura rather than the skull occurred [62], suggesting that a more replicative injury is produced when a craniotomy is avoided. Similarly it appears that larger tip sizes in mature rats $(6-10 \mathrm{~mm})$ [36,59-61] produce less focal structural damage and thus may be more appropriate for reproducing concussive insults, with only smaller tips sizes associated with development of areas of hemorrhage [43,62], although this was prevented when strike depth was decreased to $1 \mathrm{~mm}$. [58].

A potential criticism of these models is that although the head is struck directly, the model is less able to generate either rotational or linear acceleration forces due to the typical placement of the head within a stereotaxic device, and thus cannot model the mechanical forces that typically induce concussions clinically [44]. To assist in this modifications have been utilized within 
some studies, including replacement of the stereotaxic device with a molded, gel filled base [36] or placement of animals within a plastic restraint cone on a foam bed [35] to allow more movement of the head, with further characterization needed to analyze the specific types of forces generated.

Studies employing modifications of the CCI model to generate repeated concussion currently use a range of impact parameters, with acceleration ranging from 3.5 to $6 \mathrm{~m} / \mathrm{s}$ and dwell time from 31.5 to $500 \mathrm{~ms}$. Notably many studies do not provide objective measurements of injury severity, such as the presence of an apneic period or loss of righting reflex (LORR) [35,59,60,62], making it difficult to compare studies utilizing different injury parameters or to assess whether the impacts produced are likely to be concussive or subconcussive. Similarly injury schedules vary (see Table 2), with some employing a small number of injuries (2-5) with interinjury intervals ranging from 24 to $72 \mathrm{~h}[36,42,43,59,60,62,63]$, while three studies explored the effects of larger number of injuries: 30 at $24 \mathrm{~h}$ intervals [36], six impacts $2 \mathrm{~h}$ apart for 7 days [35] or 24-32 over 3-4 months [64]. Indeed it is evident that the interinjury interval can have significant effects, with Winston et al. finding that there was a greater effect on synaptic loss with an interinjury interval of 7 days rather than $24 \mathrm{~h}$ with a large number of injuries [36]. This appears counterintuitive given the known window of vulnerability whereby a second injury has been shown to have more lasting impacts [47], but perhaps indicates some adaptation when a large number of injuries are sustained within a short space of time, which is not seen with the longer interval. Further investigation will be needed to see the effect of a large number of injuries at greater intervals on other aspects seen in CTE, such as behavioral changes and tau phosphorylation.

Nonetheless many of these models do replicate some features associated with the sequelae of repeated concussion, and importantly many look at the long-term effects (up to 1 year post injury), which is important when attempting to replicate CTE such as neuropathology. Unsurprisingly all studies reported persistent neuroinflammation, as seen by increased astrocytic and microglial reactivity following repeat injury [36,5961], although evidence of enhanced tau phosphorylation, the key diagnostic feature of CTE was not consistently reported. Luo et al. saw increased pTau immunoreactivity in regions including the hippocampus and cortex at 6 months following three injuries spaced $24 \mathrm{~h}$ apart, while Petraglia et al. similarly reported enhanced tau phosphorylation at 6 months post injury in the cortex and amygdala, whereas hippocampal pTau had subsided at this point, despite a vastly different injury schedule (42 impacts in 5 days).
In contrast Winston et al. found that delivering 20 impacts over a 4 week period ( 5 daily impacts a week) to 18 month $3 x \operatorname{TgAd}$ mice did not cause an increase in levels of pTau at $24 \mathrm{~h}$ or 1 month following injury. Of note repeated injury is seen more commonly in younger populations and age at impact may affect the likelihood of increasing tau phosphorylation. Indeed Ojo et al. utilizing transgenic 12 weeks old htau mice found significantly increased levels of phosphorylated and aggregated tau at 3 months post injury within the cortex when mice were exposed to highly repetitive mTBI (24 or 32 impacts within 4 months) [64].

Other key aspects of CTE are the development of behavioral symptoms including increased anxiety, depression and cognitive deficits [14]. The majority of papers reported cognitive deficits, although these appeared shortly after injury (in the first week), with some reporting improvement at later time-points [60] or persistence to 6 months post injury [59,61]. None saw the emergence of cognitive deficits over time [59-61], which would represent a more consistent pattern to what is seen clinically [17] and may indicate that the current CCI models are too severe, but could also relate to the difficulty in detecting subtle cognitive deficits in rodents. Notably Winston et al. who did not find evidence of cognitive deficits on the Morris water maze (MWM), did see an emergence of anxiety-like behavior at 1 year post injury that was not evident at 6 months, suggesting a progressive, rather than static, disease course [36]. As such, it is evident that there are a number of models based on modification of the CCI device that can replicate aspects seen clinically following rmTBI, although there are also limitations due to the difficulty in generating the same mechanical forces seen clinically.

\section{FP injury}

The lateral FP (LFP) model is the most extensively used and characterized model of experimental TBI and is easily adapted to produce milder injuries by decreasing the force of the fluid pulse [67]; however, there are relatively few studies utilizing it to investigate the effects of repeated injury $[40,41,46,68,69]$. Injury is induced with FP by performing a craniotomy and applying a fluid pressure pulse to the intact dura, caused by the striking of a pendulum against a piston attached to a reservoir of fluid, producing displacement and deformation of neural tissue [70]. As such, it does not reproduce the linear and rotational forces that generate concussive injuries clinically.

Previous literature has suggested that mild to moderate injury can be administered between (0.9-2.1 atm) [71], and indeed reports using LFP to induce repeated $\mathrm{mTBI}$ herein use pressures that fall within 


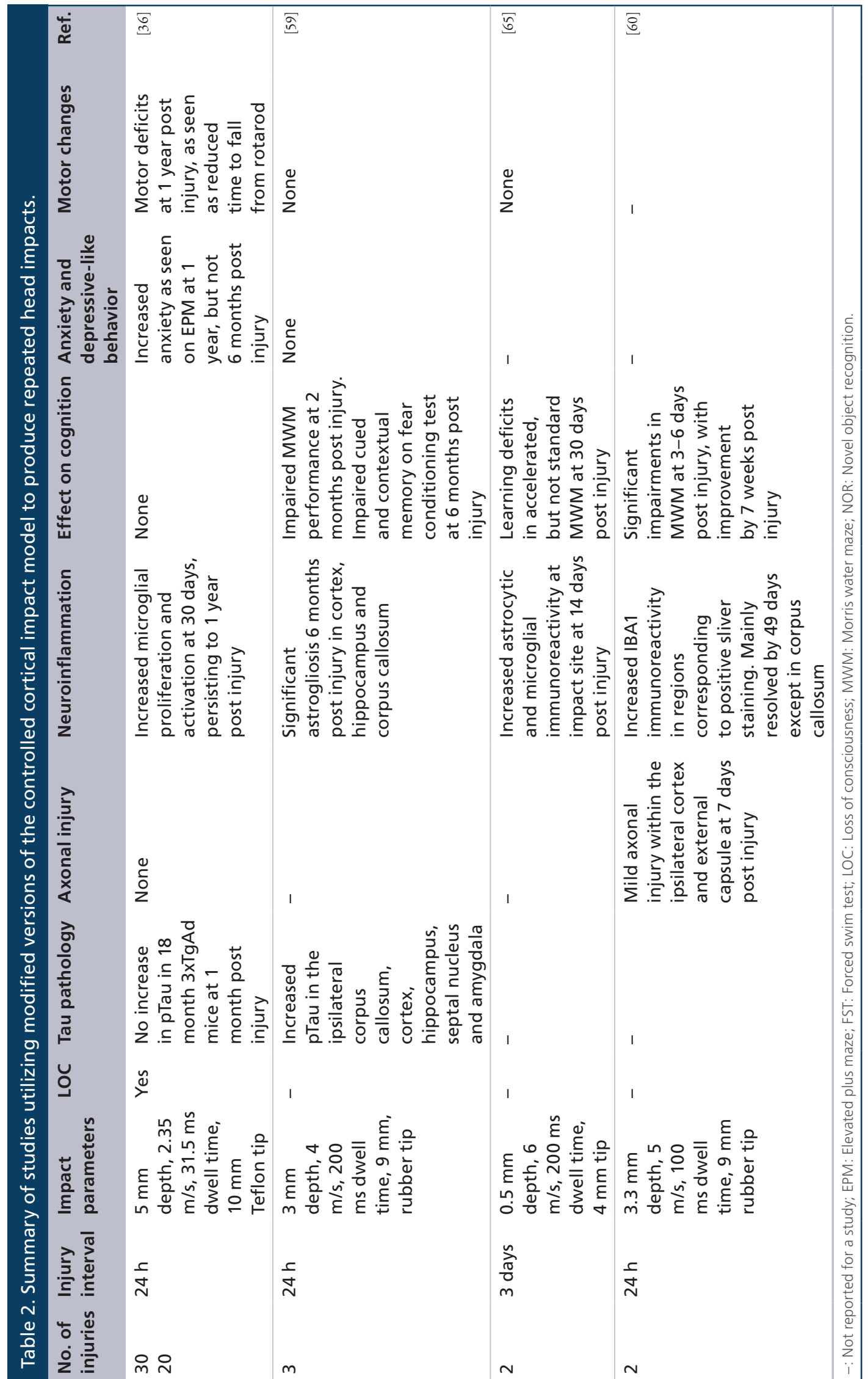




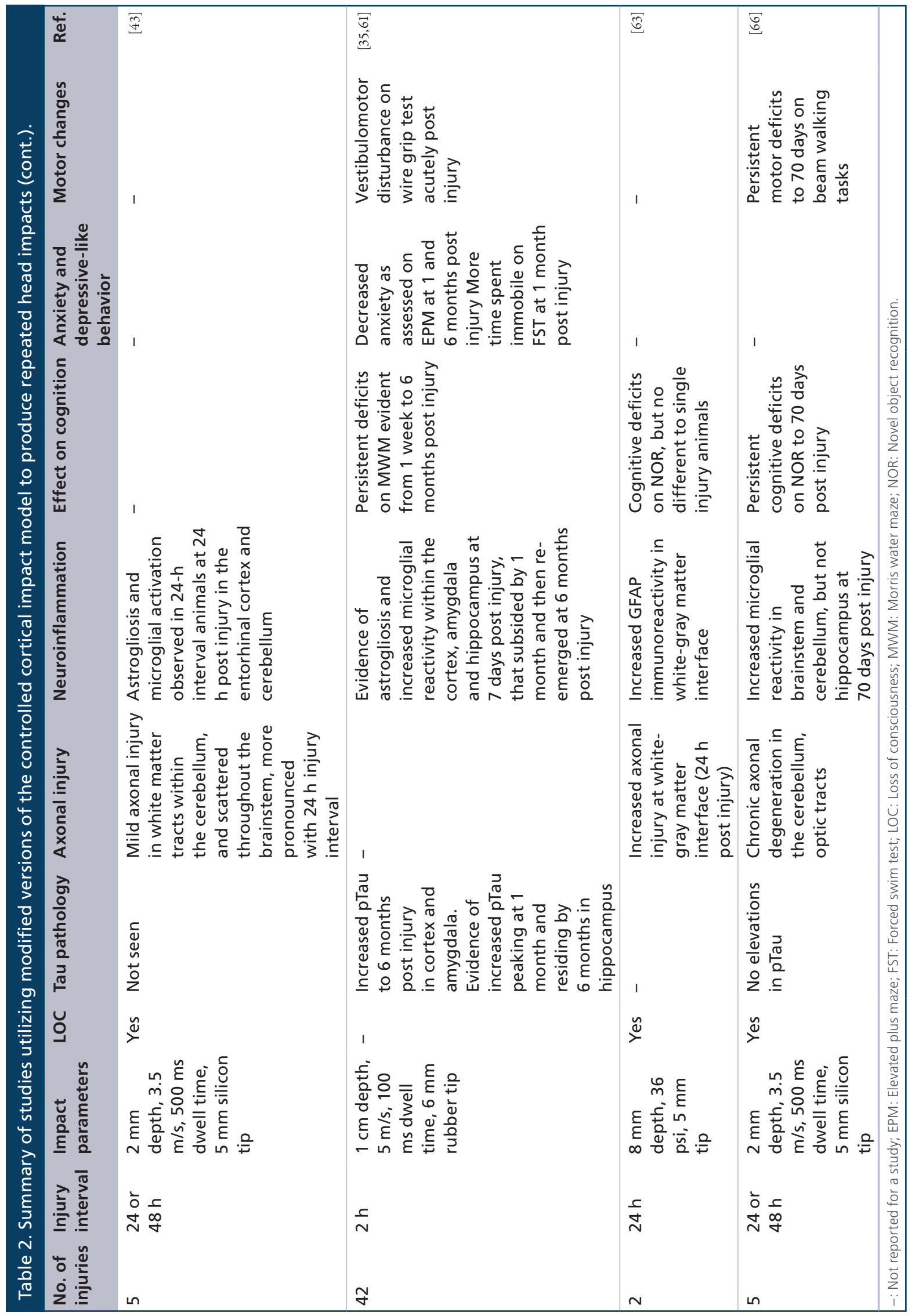




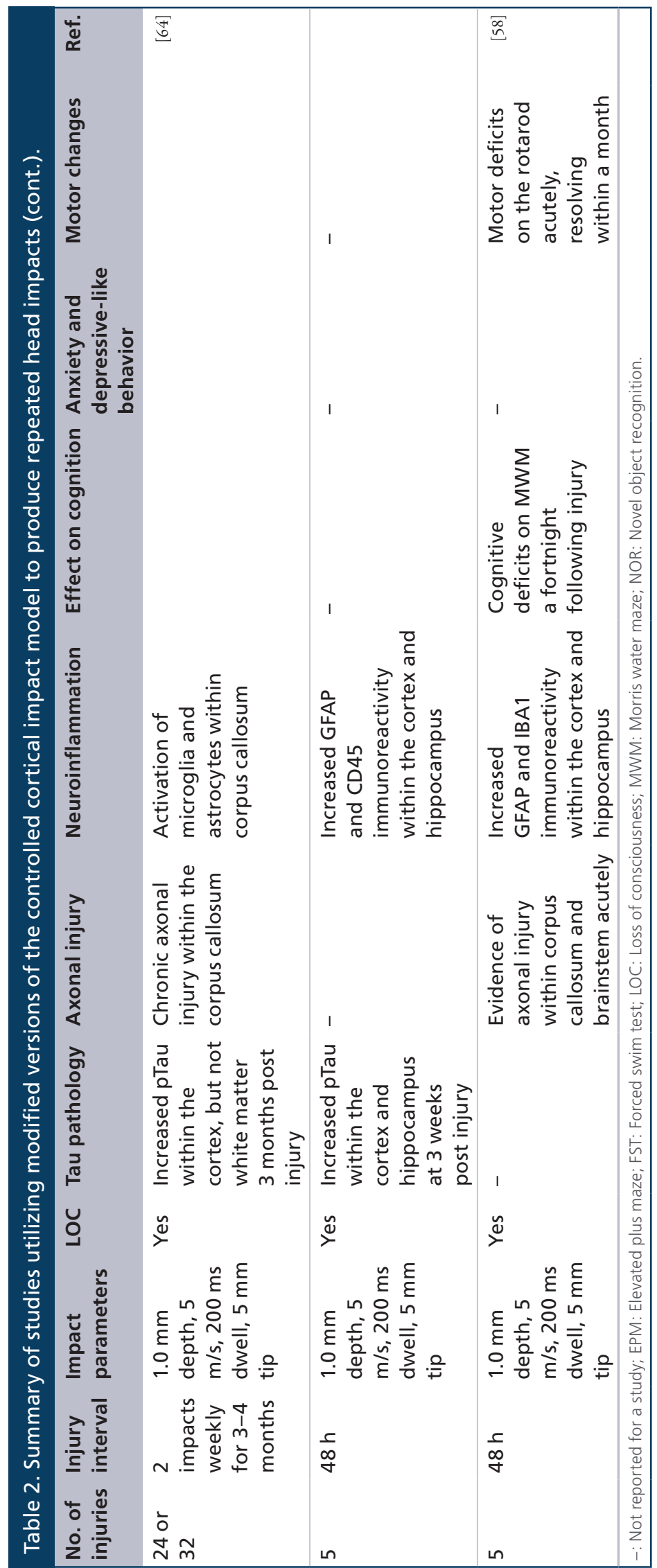




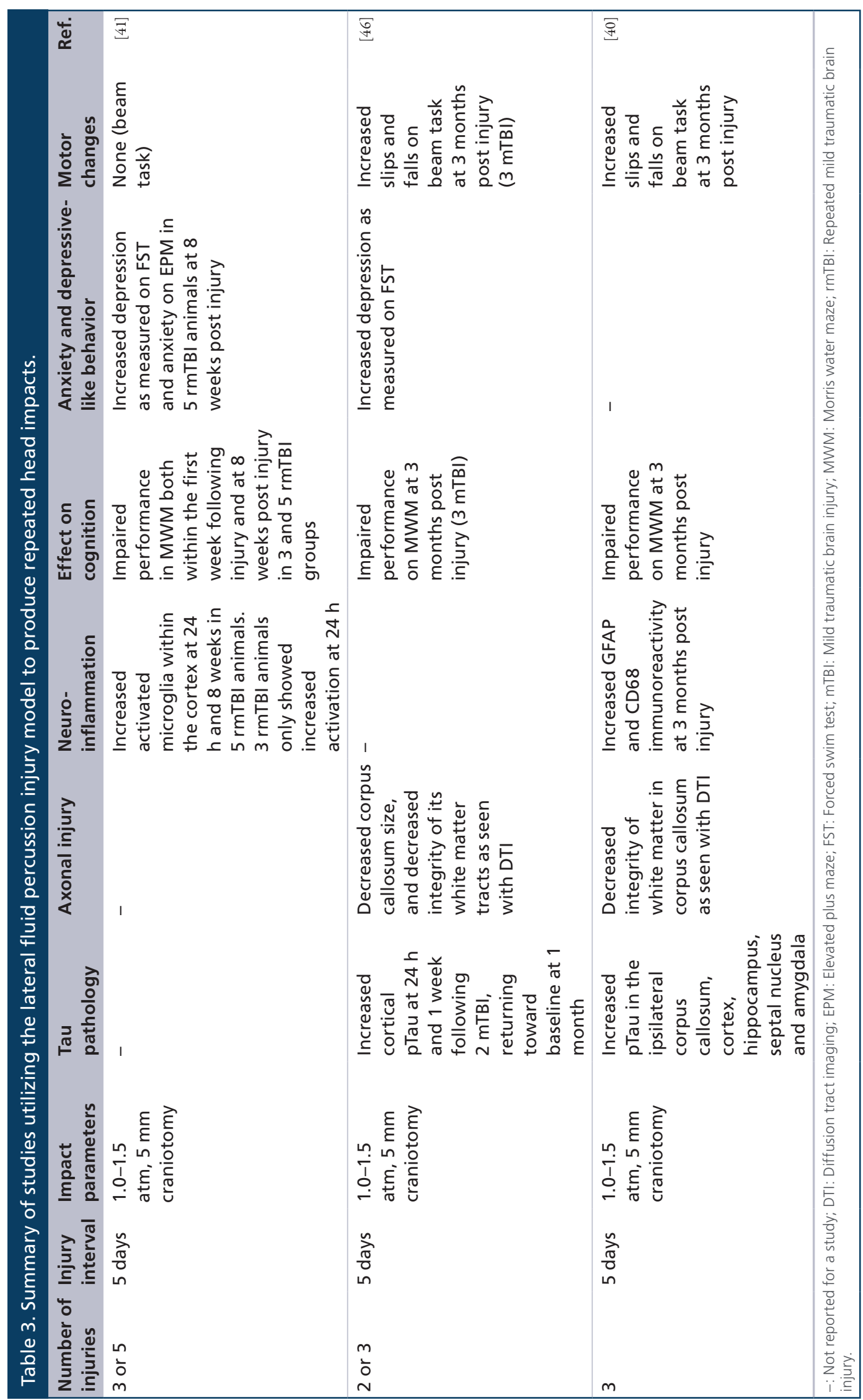




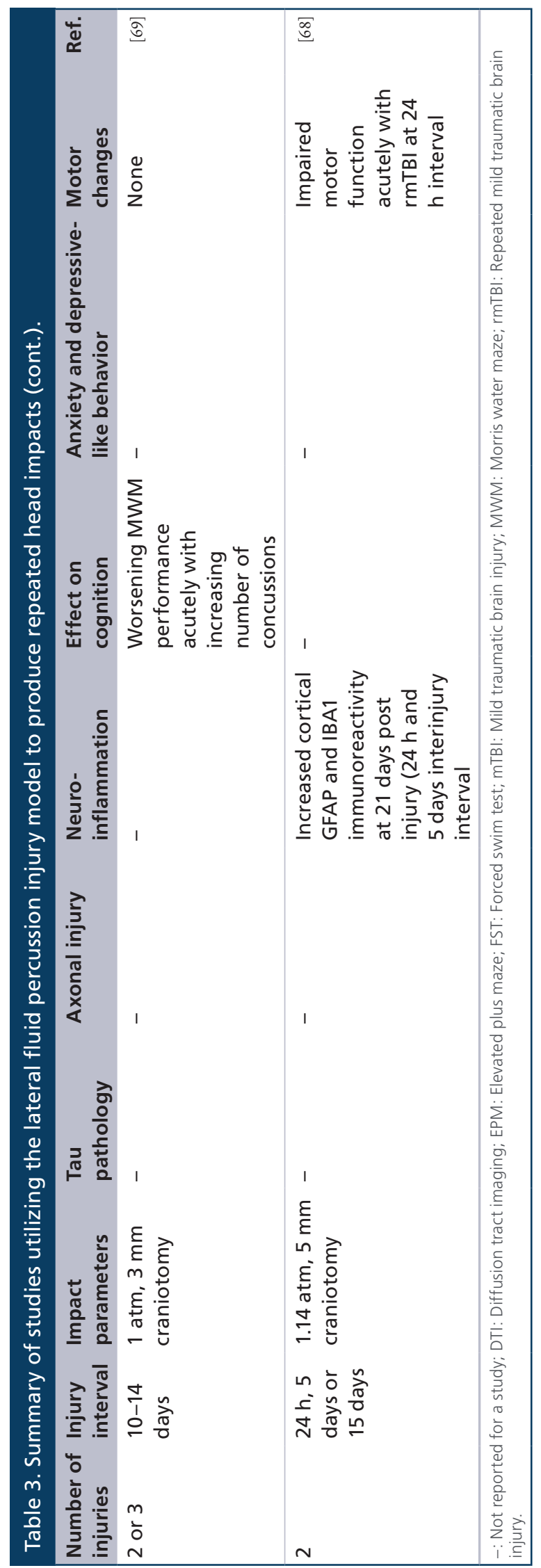




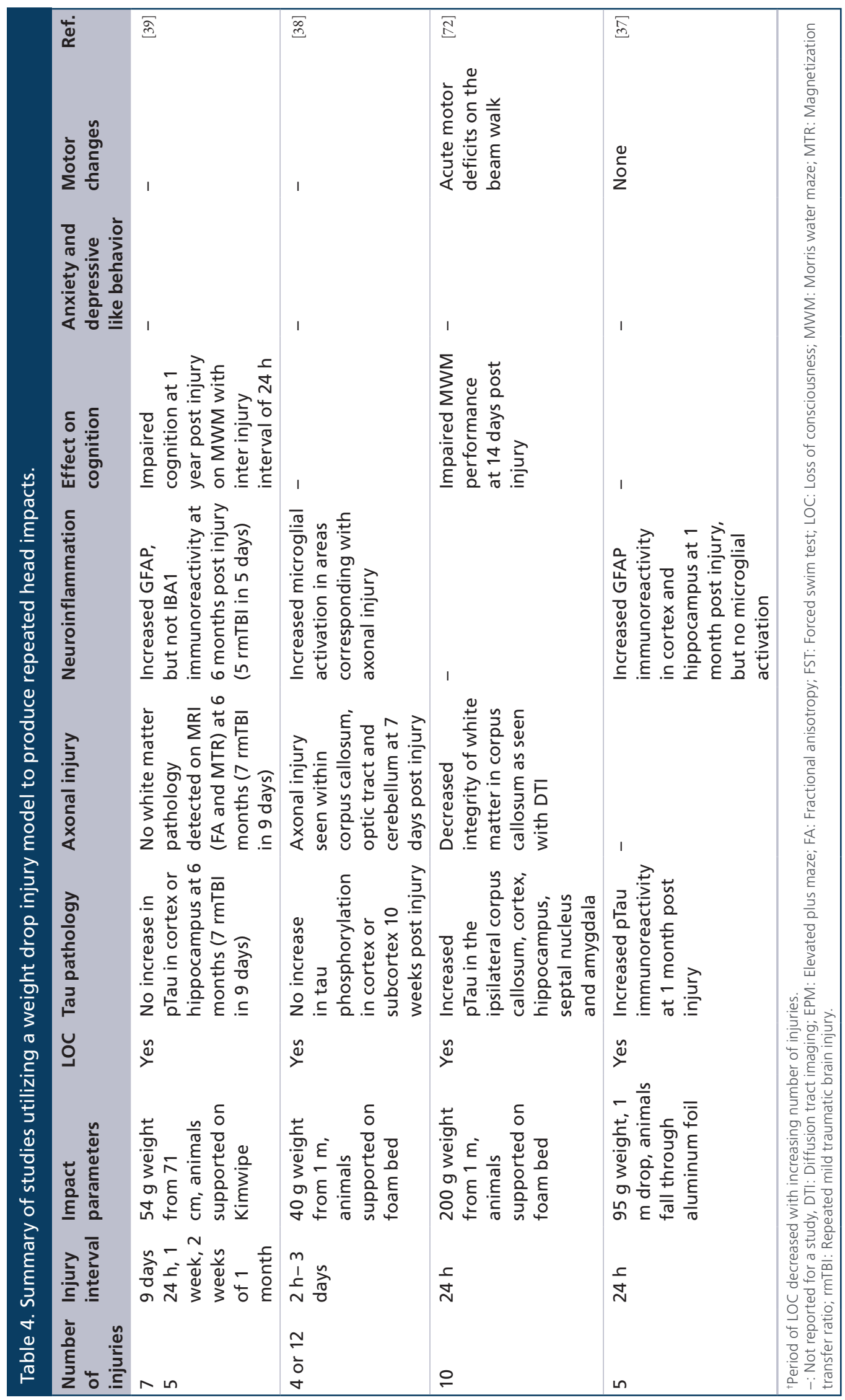




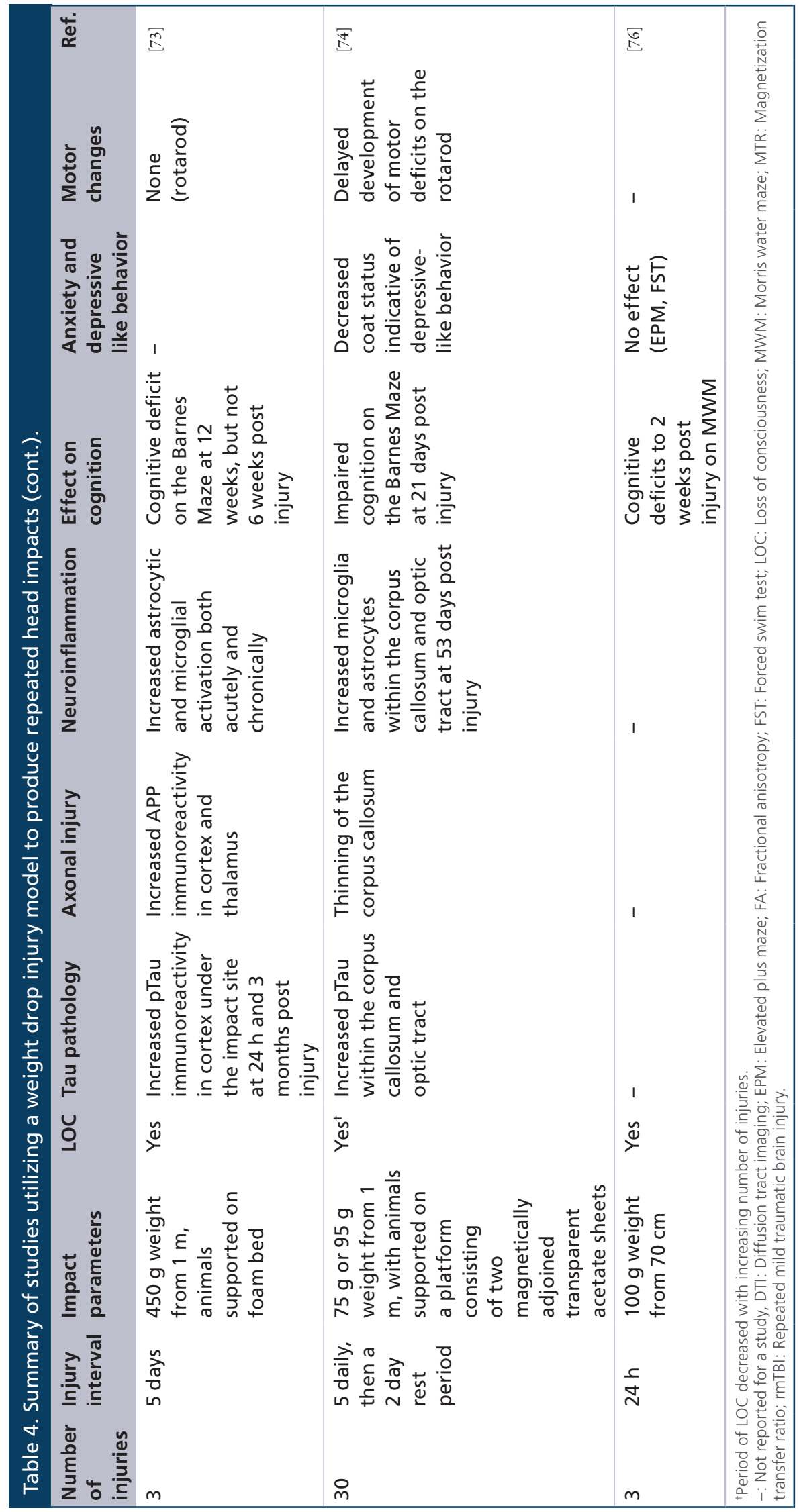


the smaller end of this scale (1.0-1.5 atm; Table 3). One difficulty with use of the model for repeat injuries is the necessity for a craniotomy to be performed to administer the injury. This increases the risk of other factors such as wound infection and the animals removing the screw/cement complexes that are necessary to induce injury [69]. Furthermore it limits the number of injuries that are able to be delivered with five injuries the highest reported [41], unlike the modified CCI models and weight drop models. In addition repeated LFP appears to cause significant cortical damage, when impacts are spaced closely together (within $24 \mathrm{~h}$ ) or when more than three impacts are given spaced 5 days apart $[40,41,46]$, a feature not suggestive of the type of pathology seen in CTE, which is a progressive neurodegenerative disease.

However, some features reported to be related to the long-term effects of repeated concussion, with persistent neuroinflammation to 3 months post injury (the latest time point studied) [40,41,68], evidence of white matter damage $[40,46]$ and increased tau phosphorylation within the cortex [46]. It should be noted that with two injuries spaced 5 days apart increased tau phosphorylation was more prominent acutely after injury (at $24 \mathrm{~h}$ and 1 week) returning toward sham level by 1 month post injury, with an increase to three repeat injuries associated with increased tau phosphorylation to 3 months post injury [46]. Like the modified repeat CCI models, multiple LFP injuries are associated with cognitive deficits both acutely [41,69] and chronically $[40,41,46,69]$, although this model has been associated with more significant motor impairments most likely related to the degree of cortical injury $[40,46,68]$.

\section{Closed head weight drop}

Closed head injury models involve the application of force directly onto the intact skull, which causes movement of the unrestricted head, including lateral and rotational forces, as seen in concussive insults. This produces a diffuse injury, with no reports of cortical contusions of hemorrhage unlike some CCI [43,62], or FPI models $[40,41,46]$. Typically a weight is dropped from a height, either onto the head itself, or onto a metal helmet applied to the skull to prevent the skull fracture, with head movement facilitated by placement of the animal within a foam bed $[38,72,73]$ or by allowing the animal to free fall from the surface they were resting on (aluminum foil, Kim wipes of magnetic sheets) into a foam bed below [37,39,74]. The latter allows unrestricted movement, and hence may promote more rotational injury, which is known to cause the shear strain critical in concussive impacts, although biomechanical studies on these forces have yet to be reported. Indeed it should be noted that there are similarities between the weight drop models and modifications of the CCI, such as that utilized by Petraglia et al. [35,61] where the head is not restrained, with the key difference being how the force to the head is generated.

Notably all reports examined here suggest that the impacts delivered lead to increased LORR [37-39,72-74], indicative of concussive impacts and hence the more severe end of sporting injuries. Future studies could alter parameters to include subconcussive impacts to investigate the effect of combining these types of impacts. Furthermore, Briggs et al. who utilized the highest number of impacts (30) found that LORR decreased with subsequent impact suggesting some adaption to the impact, an important point to consider when using LORR as a measure of impact severity, especially when animals are subject to a large number of head impacts spaced close together $(5$ impacts/week for 6 weeks) [74].

Similar to the models discussed above, weight drop models similarly report variable neuropathological and behavioral findings associated with the long-term consequences of repeated concussion. Again this may be in part be caused by variability of the number of impacts employed, with as low as three [73] and as high as 30 [74], interinjury intervals ranging from $24 \mathrm{~h}$ to 5 days and the weight and hence force of impact reported as between 40-95 $\mathrm{g}$ in mouse studies [37-39,74] and $200-450 \mathrm{~g}$ in rat studies $[72,73]$ with release of the weight typically from $1 \mathrm{~m}$. As with other concussion models, increased neuroinflammation was consistently reported in studies incorporating weight drop models [37-39,73-74], up to 6 months post injury, although intriguingly both Mannix et al. and Kane et al. reported increased astrocytic, but not microglial activation at chronic time-points suggested there could be a differential response of these two immune cells [37,39]. Similar to the CCI models, increased tau phosphorylation was not a consistent feature, with reports of acutely increased pTau in some studies within areas such as the cortex, hippocampus and white matter tracts [37,72-74], while Mannix et al. reported normal levels of pTau at 6 months following $7 \mathrm{rmTBI}$ in 9 days [39] and Xu et al. similarly found no changes in pTau at 10 weeks following 12 hits over 7 days [38]. Given the considerable differences within the studies that reported positive findings and those with negative tau findings (see Table 4) it is difficult to determine the key factors within injury models that allow for the development of abnormal tau phosphorylation post injury, with greater exploration of both how the mechanical forces induced and their severity and frequency influence tau phosphorylation, as well as the role of different tau phosphorylation sites may be needed in future studies. Tau can be phosphorylated at up to 85 different sites [75], so subtle changes 
in tau phosphorylation state can be missed depending on the antibodies utilized.

As discussed earlier, other key aspects of CTE are the development of behavioral symptoms including increased impulsivity, depression and cognitive deficits [14]. Like the other injury models, the weight drop model was similarly associated with cognitive deficits, both acutely within the first 2 weeks following injury [72] and persisting to 1 year post injury [39]. Mannix et al. did see a protective effect of increased interinjury interval with impaired performance on the MWM at 6 months following injury with a shorter gap between injuries ( $24 \mathrm{~h}$ or week), but not at longer intervals ( 2 weeks, 4 weeks). Furthermore, in one study a progressive cognitive deficit, suggestive of ongoing neurodegeneration was seen with increased escape latency on the Barnes Maze seen at 12 weeks, but not 6 weeks post injury [73]. Few studies looked at additional behavioral symptoms with reports of delayed motor deficits developing following a large number of impacts (30 over 6 weeks) and persistent depressive-like behavior in the same model, with further study needed, especially given the suggestion that psychological symptoms may be the first manifestation of chronic neuropathology associated with repeated head impacts [17].

\section{Rotational acceleration models}

To date no pure rotational acceleration models (without head impact) have been developed to study the effects of repeated insults to the brain on later neurodegeneration. This is in line with the clinical literature where typically an impact to the head is received that then leads to rapid acceleration [1]. This is most closely replicated by the weight drop models where animals are free to fall from the surface they were resting on (aluminum foil, Kim wipes of magnetic sheets) into a foam bed below [37,39,74]. Nonetheless there are currently rotational acceleration models have been developed in the rat [77], rabbit [78], pig [79] and primate [80] that could be adapted to allow for milder injuries. Gutierrez et al. developed a rabbit model, where impact from a pneumatic cylinder was transferred to the skull surface to produce a maximal rotational velocity of $212 \mathrm{krads} / \mathrm{s}^{2}$ [78]. This led to extensive subarachnoid hemorrhage, so would need to be scaled to produce a milder injury. In rodents, Xiao-Sheng et al. developed a model where the head was rapidly rotated $90^{\circ}$ in the coronal plane at a rotation reported to be $1.806 \times 10^{5}$ $\mathrm{rad} /$ second $^{2}$ [77]. It is unclear whether this would be sufficient based on the Holbourn scaling relationship to accurately represent forces seen in human TBI, given the smaller size of the rat brain [34]. Notably even at these forces, extensive subarachnoid hemorrhaging was also noted [77], suggesting that it may be difficult to accurately represent rotational forces in small animal models given the differences in size and nature of their brains. Indeed models have been developed in larger gyrencephalic brains as discussed in the next section.

\section{Adaptation of gyrencephalic models of mTBI to investigate repetitive insults}

In addition to continuing to improve rodent models, another avenue to investigate different aspects of the effects of repetitive impacts on the later development of neurodegeneration may be to modify existing large animal models. There are structural differences between the rodent (lissencephalic) and human (gyrencephalic) brains. Importantly mechanical forces are distributed differently, with linear forces seen in lissencephalic brains concentrated parallel with the surface of the brain, compared with at the base of the sulci in gyrencephalic brains [81-83]. Computer modeling of the patterns of stress in the gyrencephalic brain [81-83] are remarkably similar to the tau deposition patterns observed in CTE, and may suggest that tau deposition occurs at areas of high mechanical stress [16] an idea that has yet to be confirmed experimentally. Indeed, to date no repeat injury models have been conducted in gyrencephalic brains, and only two model of mTBI. Browne et al. modified a miniature swine model of TBI where a pneumatic actuator is used to induce rotational acceleration of the head, using forces of up to $28,000 \mathrm{rad} / \mathrm{s}^{2}[79]$, higher than the reported range of 5022-7912 rad/s $\mathrm{s}^{2}$ reported clinically $[23,24,27,28]$, which was described as a mechanism to equate for the smaller size of the brain within the miniature swine. Nevertheless and impact within the axial plane produced a mTBI with loss of consciousness of between 10 and 35 minutes associated with mild axonal injury [79], thereby equating to a more severe clinical concussion. Older studies have also been conducted in monkeys, with acceleration of the head without impact, severity of injury depended on the direction of head movement, with a sagittal head motion producing a loss of consciousness for $<15 \mathrm{~min}$, without evidence of diffuse axonal injury [80]. The ability to produce concussive insults in larger animals provides a basis for further investigations utilizing large animal models to investigate aspects of repeated head impacts in the gyrencephalic brain.

\section{Conclusion}

In recent years a desire to understand the nature of sports-related head injury has led to resurgence in interest in modeling aspects of repeated injury. This has allowed a greater appreciation of the idea of a window of vulnerability following a concussive event, whereby a subsequent concussion can have more detrimental effects and greater efforts in preventing premature return to play. However, how a prolonged history of head impacts, both concussive and subconcussive, as seen in NFL players, may increase 
the risk of later developing the neurodegenerative disease CTE is less clear. A number of rodent models have been generated that aim to replicate different aspects of concussive insults, with studies varying markedly in how the concussive insult is induced, the injury severity utilized, the number of insults and the interinjury variability. Unsurprisingly this had led to a variable ability to replicate key aspects of CTE, such as increased tau phosphorylation and development of cognitive and behavioral deficits. Indeed no models have been able to replicate the staged progression of tau pathology, where it begins in the superficial cortex and then spreads to other regions such as the hippocampus, or its associated features such as TDP-43 immunoreactive nuclear inclusions. This is in part due to the differences in murine and human tau, but even transgenic models have not consistently reported increased tau phosphorylation and development of NFTs. Later time points may also need to be investigated, although some reported cases of CTE have been in young players [84]. Progression of behavioral deficits has also been rarely seen in animal reports to date and area that requires further investigation. Another area of potential investigation is to determine how the gyrencephalic brain responds to mechanical insults and how this may influence tau phosphorylation and deposition and the potential later development of neurodegeneration, although there are technical limitations to the number of injuries that could be delivered in these models.

\section{Future perspective}

Animal models of repeated mTBI will continue to evolve, and may begin to include injuries of varying severity and varying interinjury intervals to try and better approximate the clinical situation. With improving genetic technology, newer transgenic rodent models may be available to better allow modeling of tau dynamics within our rodent models. A better understanding of how a history of repeated injury may interact with lifestyle factors, such as drug addiction may also be incorporated in our models, given the vast majority of people who receive multiple head impacts do not go to develop neurodegeneration. Furthermore it is proposed that research will branch into large animal models to utilize their gyrencephalic brains to understand the differing effects of mechanical forces and how this influences tau phosphorylation.

\section{Author contributions}

All authors were involved in surveying the literature and writing and reviewing the presented paper.

\section{Financial \& competing interests disclosure}

The authors have no relevant affiliations or financial involvement with any organization or entity with a financial interest in or financial conflict with the subject matter or materials discussed in the manuscript. This includes employment, consultancies, honoraria, stock ownership or options, expert testimony, grants or patents received or pending, or royalties.

No writing assistance was utilized in the production of this manuscript.

\section{Open access}

This work is licensed under the Creative Commons Attribution 4.0 License. To view a copy of this license, visit http://creativecommons.org/licenses/by/4.0/

\section{Executive summary}

- A history of repeated head injury is associated with the risk of later developing the neurodegenerative disease chronic encephalopathy, which involves the graded deposition of hyperphosphorylated tau, accompanied by persistent neuroinflammation and evidence of white matter damage.

- In order to understand the link between repeated head injury and later neurodegeneration, animal models have been developed to model different aspects.

- These are typically based on adaptations of traditional traumatic brain injury models in cortical impact, fluid percussion and weight drop, with modifications to suit a more concussive insult.

- Currently a wide range of different parameters are in use making comparisons between studies.

- There has been variable success in replicating key features of chronic traumatic encephalopathy such as increased tau phosphorylation and progressive behavioral deficits.

\section{References}

1 Mccrory P, Meeuwisse WH, Aubry M et al. Consensus statement on concussion in sport: the 4th International Conference on Concussion in Sport held in Zurich, November 2012. Br. J. Sports Med. 47(5), 250-258 (2013).

2 Marshall CM. Sports-related concussion: a narrative review of the literature. J. Can. Chiropr. Assoc. 56(4), 299-310 (2012).

3 Khurana VG, Kaye AH. An overview of concussion in sport. J. Clin. Neurosci. 19(1), 1-11 (2012).
4 Finch CF, Clapperton AJ, Mccrory P. Increasing incidence of hospitalisation for sport-related concussion in Victoria, Australia. Med. J. Aust. 198(8), 427-430 (2013).

5 Harmon KG, Drezner JA, Gammons M et al. American Medical Society for Sports Medicine position statement: concussion in sport. Br. J. Sports Med. 47(1), 15-26 (2013).

6 Mckee AC, Cairns NJ, Dickson DW et al. The first NINDS/NIBIB consensus meeting to define 
neuropathological criteria for the diagnosis of chronic traumatic encephalopathy. Acta Neuropathol. 131(1), 75-86 (2016).

7 Guskiewicz KM, Marshall SW, Bailes J et al. Association between recurrent concussion and late-life cognitive impairment in retired professional football players. Neurosurgery 57(4), 719-726; discussion 719-726 (2005).

8 Martland H. Punch drunk. J. Am. Med. Assoc 91, 1103-1107 (1928).

9 Millspaugh J. Dementia pugilistica. U. S. Naval Med. Bull 35, 297-303 (1937).

10 Corsellis JA, Bruton CJ, Freeman-Browne D. The aftermath of boxing. Psychol. Med. 3(3), 270-303 (1973).

11 Omalu BI, Dekosky ST, Minster RL, Kamboh MI, Hamilton RL, Wecht CH. Chronic traumatic encephalopathy in a National Football League player. Neurosurgery 57(1), 128-134; discussion 128-134 (2005).

12 Omalu BI, Fitzsimmons RP, Hammers J, Bailes J. Chronic traumatic encephalopathy in a professional American wrestler. J. Forensic Nurs. 6(3), 130-136 (2010).

13 Omalu BI, Hamilton RL, Kamboh MI, Dekosky ST, Bailes J. Chronic traumatic encephalopathy (CTE) in a National Football League player: case report and emerging medicolegal practice questions. J. Forensic Nurs. 6(1), 40-46 (2010).

14 Mckee AC, Stern RA, Nowinski CJ et al. The spectrum of disease in chronic traumatic encephalopathy. Brain $136(\mathrm{Pt}$ 1), 43-64 (2013).

15 Stern RA, Riley DO, Daneshvar DH, Nowinski CJ, Cantu $\mathrm{RC}$, Mckee AC. Long-term consequences of repetitive brain trauma: chronic traumatic encephalopathy. $P M R 3(10$ Suppl. 2), S460-S467 (2011).

16 Mckee AC, Cantu RC, Nowinski CJ et al. Chronic traumatic encephalopathy in athletes: progressive tauopathy after repetitive head injury. J. Neuropathol. Exp. Neurol. 68(7), 709-735 (2009).

17 Stern RA, Daneshvar DH, Baugh CM et al. Clinical presentation of chronic traumatic encephalopathy. Neurology 81(13), 1122-1129 (2013).

18 Mckee AC, Gavett BE, Stern RA et al. TDP-43 proteinopathy and motor neuron disease in chronic traumatic encephalopathy. J. Neuropathol. Exp. Neurol. 69(9), 918-929 (2010).

19 Meaney DF, Smith DH. Biomechanics of concussion. Clin. Sports Med. 30 (1), 19-31, vii (2011).

20 Urban JE, Davenport EM, Golman AJ et al. Head impact exposure in youth football: high school ages 14 to 18 years and cumulative impact analysis. Ann. Biomed. Eng. 41(12), 2474-2487 (2013).

21 Kimpara H, Iwamoto M. Mild traumatic brain injury predictors based on angular accelerations during impacts. Ann. Biomed. Eng. 40 (1), 114-126 (2012).

22 Newman JA, Beusenberg MC, Shewchenko N, Withnall C, Fournier E. Verification of biomechanical methods employed in a comprehensive study of mild traumatic brain injury and the effectiveness of American football helmets. J. Biomech. 38(7), 1469-1481 (2005).
23 Guskiewicz KM, Mihalik JP, Shankar V et al. Measurement of head impacts in collegiate football players: relationship between head impact biomechanics and acute clinical outcome after concussion. Neurosurgery 61(6), 1244-1252; discussion 1252-1243 (2007).

24 Rowson S, Duma SM, Beckwith JG et al. Rotational head kinematics in football impacts: an injury risk function for concussion. Ann. Biomed. Eng. 40 (1), 1-13 (2012).

25 Mcintosh AS, Patton DA, Frechede B, Pierre PA, Ferry E, Barthels $\mathrm{T}$. The biomechanics of concussion in unhelmeted football players in Australia: a case-control study. BMJ Open 4(5), e005078 (2014).

26 Rowson S, Brolinson G, Goforth M, Dietter D, Duma $S$. Linear and angular head acceleration measurements in collegiate football. J. Biomech. Eng. 131(6), 061016 (2009).

27 Mcallister TW, Ford JC, Ji S et al. Maximum principal strain and strain rate associated with concussion diagnosis correlates with changes in corpus callosum white matter indices. Ann. Biomed. Eng. 40(1), 127-140 (2012).

28 Duma SM, Manoogian SJ, Bussone WR et al. Analysis of real-time head accelerations in collegiate football players. Clin. J. Sport Med. 15(1), 3-8 (2005).

29 Margulies SS, Thibault LE. An analytical model of traumatic diffuse brain injury. J. Biomech. Eng. 111(3), 241-249 (1989).

30 Margulies SS, Thibault LE, Gennarelli TA. Physical model simulations of brain injury in the primate. J. Biomech. 23(8), 823-836 (1990).

31 Johnson VE, Meaney DF, Cullen DK, Smith DH. Animal models of traumatic brain injury. Handb. Clin. Neurol. 127, 115-128 (2015).

32 Ommaya A, Yarnell P, Hirsch A, Harris E. Scaling of experimental data on cerebral concussion in sub-human primates to concussion threshold for man. Presented at: 11th Stapp Car Crash Conference. Anaheim, CA, USA, 10-11 October 1967.

33 Smith DH, Chen XH, Xu BN, Mcintosh TK, Gennarelli TA, Meaney DF. Characterization of diffuse axonal pathology and selective hippocampal damage following inertial brain trauma in the pig. J. Neuropathol. Exp. Neurol. 56(7), 822-834 (1997).

34 Meaney DF, Margulies SS, Smith DH. Diffuse axonal injury. J. Neurosurg. 95(6), 1108-1110 (2001).

35 Petraglia AL, Plog BA, Dayawansa $S$ et al. The spectrum of neurobehavioral sequelae after repetitive mild traumatic brain injury: a novel mouse model of chronic traumatic encephalopathy. J. Neurotrauma 31(13), 1211-1224 (2014).

36 Winston CN, Noel A, Neustadtl A et al. Dendritic spine loss and chronic white matter inflammation in a mouse model of highly repetitive head trauma. Am. J. Pathol. 186(3), 552-567 (2016).

37 Kane MJ, Angoa-Perez M, Briggs DI, Viano DC, Kreipke CW, Kuhn DM. A mouse model of human repetitive mild traumatic brain injury. J. Neurosci. Methods 203(1), 41-49 (2012).

$38 \mathrm{Xu}$ L, Nguyen JV, Lehar M et al. Repetitive mild traumatic brain injury with impact acceleration in the mouse: multifocal axonopathy, neuroinflammation, and 
neurodegeneration in the visual system. Exp. Neurol. 275(Pt 3), 436-449 (2016).

39 Mannix R, Meehan WP, Mandeville J et al. Clinical correlates in an experimental model of repetitive mild brain injury. Ann. Neurol. 74(1), 65-75 (2013).

Webster KM, Wright DK, Sun M et al. Progesterone treatment reduces neuroinflammation, oxidative stress and brain damage and improves long-term outcomes in a rat model of repeated mild traumatic brain injury. $J$. Neuroinflammation 12, 238 (2015).

41 Shultz SR, Bao F, Omana V, Chiu C, Brown A, Cain DP. Repeated mild lateral fluid percussion brain injury in the rat causes cumulative long-term behavioral impairments, neuroinflammation, and cortical loss in an animal model of repeated concussion. J. Neurotrauma 29(2), 281-294 (2012).

Ojo JO, Mouzon B, Greenberg MB, Bachmeier C, Mullan $\mathrm{M}$, Crawford F. Repetitive mild traumatic brain injury augments tau pathology and glial activation in aged hTau mice. J. Neuropathol. Exp. Neurol. 72(2), 137-151 (2013).

Bolton AN, Saatman KE. Regional neurodegeneration and gliosis are amplified by mild traumatic brain injury repeated at 24-hour intervals. J. Neuropathol. Exp. Neurol. 73(10), 933-947 (2014).

44 Angoa-Perez M, Kane MJ, Briggs DI, Herrera-Mundo N, Viano DC, Kuhn DM. Animal models of sports-related head injury: bridging the gap between pre-clinical research and clinical reality. J. Neurochem. 129(6), 916-931 (2014).

45 Forbes JA, Awad AJ, Zuckerman S, Carr K, Cheng JS. Association between biomechanical parameters and concussion in helmeted collisions in American football: a review of the literature. Neurosurg. Focus 33(6), E10, 11-16 (2012).

46 Tan XL, Wright DK, Liu S, Hovens C, O'brien TJ, Shultz SR. Sodium selenate, a protein phosphatase $2 \mathrm{~A}$ activator, mitigates hyperphosphorylated tau and improves repeated mild traumatic brain injury outcomes. Neuropharmacology 108, 382-393 (2016).

47 Longhi L, Saatman KE, Fujimoto $S$ et al. Temporal window of vulnerability to repetitive experimental concussive brain injury. Neurosurgery 56(2), 364-374; discussion 364-374 (2005).

48 Huber BR, Alosco ML, Stein TD, Mckee AC. Potential longterm consequences of concussive and subconcussive injury. Phys. Med. Rehabil. Clin. N. Am. 27(2), 503-511 (2016).

49 Daneshvar DH, Goldstein LE, Kiernan PT, Stein TD, Mckee AC. Post-traumatic neurodegeneration and chronic traumatic encephalopathy. Mol. Cell. Neurosci. 66(Pt B), 81-90 (2015).

50 Daneshvar DH, Nowinski CJ, Mckee AC, Cantu RC. The epidemiology of sport-related concussion. Clin. Sports Med. 30(1), 1-17, vii (2011).

51 Houck Z, Asken B, Bauer R, Pothast J, Michaudet C, Clugston J. Epidemiology of sport-related concussion in an NCAA division I football bowl subdivision sample. Am. J. Sports Med. 44(9), 2269-2275 (2016).

52 Sengupta $P$. The laboratory rat: relating its age with human's. Int. J. Prev. Med. 4(6), 624-630 (2013).
53 Andreollo NA, Santos EF, Araujo MR, Lopes LR. Rat's age versus human's age: what is the relationship? Arq. Bras. Cir. Dig. 25(1), 49-51 (2012).

54 Guskiewicz KM, Marshall SW, Bailes J et al. Recurrent concussion and risk of depression in retired professional football players. Med. Sci. Sports Exerc. 39(6), 903-909 (2007).

55 Peskind ER, Brody D, Cernak I, Mckee A, Ruff RL. Military- and sports-related mild traumatic brain injury: clinical presentation, management, and long-term consequences. J. Clin. Psychiatry 74(2), 180-188; quiz 188 (2013).

56 Barrio JR, Small GW, Wong KP et al. In vivo characterization of chronic traumatic encephalopathy using [F-18]FDDNP PET brain imaging. Proc. Natl Acad. Sci. USA 112(16), E2039-E2047 (2015).

57 Romine J, Gao X, Chen J. Controlled cortical impact model for traumatic brain injury. J. Vis. Exp. (90), e51781 (2014).

58 Mouzon B, Chaytow H, Crynen G et al. Repetitive mild traumatic brain injury in a mouse model produces learning and memory deficits accompanied by histological changes. $J$. Neurotrauma 29(18), 2761-2773 (2012).

59 Luo J, Nguyen A, Villeda S et al. Long-term cognitive impairments and pathological alterations in a mouse model of repetitive mild traumatic brain injury. Front. Neurol. 5, 12 (2014).

60 Shitaka Y, Tran HT, Bennett RE et al. Repetitive closed-skull traumatic brain injury in mice causes persistent multifocal axonal injury and microglial reactivity. J. Neuropathol. Exp. Neurol. 70(7), 551-567 (2011).

61 Petraglia AL, Plog BA, Dayawansa $S$ et al. The pathophysiology underlying repetitive mild traumatic brain injury in a novel mouse model of chronic traumatic encephalopathy. Surg. Neurol. Int. 5, 184 (2014).

62 Huang L, Coats JS, Mohd-Yusof A et al. Tissue vulnerability is increased following repetitive mild traumatic brain injury in the rat. Brain Res. 1499, 109-120 (2013).

63 Prins ML, Hales A, Reger M, Giza CC, Hovda DA. Repeat traumatic brain injury in the juvenile rat is associated with increased axonal injury and cognitive impairments. Dev. Neurosci. 32(5-6), 510-518 (2010).

64 Ojo JO, Mouzon B, Algamal M et al. Chronic repetitive mild traumatic brain injury results in reduced cerebral blood flow, axonal injury, gliosis, and increased T-tau and tau oligomers. J. Neuropathol. Exp. Neurol. 75(7), 636-655 (2016).

65 Huang C, Xia PY, Zhou H. Sustained expression of TDP-43 and FUS in motor neurons in rodent's lifetime. Int. J. Biol. Sci. 6(4), 396-406 (2010).

66 Bolton Hall AN, Joseph B, Brelsfoard JM, Saatman KE. Repeated closed head injury in mice results in sustained motor and memory deficits and chronic cellular changes. PLoS ONE 11(7), e0159442 (2016).

67 Corrigan F, Ziebell JM, Vink R. Models of rodent cortical traumatic brain injury. Neuromethods 62, doi:10.1007/978-161779-301-1_11 (2011) (Epub ahead of print).

68 Selwyn RG, Cooney SJ, Khayrullina G et al. Outcome after repetitive mild traumatic brain injury is temporally 
related to glucose uptake profile at time of second injury. J. Neurotrauma 33(16), 1479-1491 (2016).

69 Deross AL, Adams JE, Vane DW, Russell SJ, Terella AM, Wald SL. Multiple head injuries in rats: effects on behavior. J. Trauma 52(4), 708-714 (2002).

70 Mcintosh TK, Vink R, Noble L et al. Traumatic brain injury in the rat: characterization of a lateral fluid-percussion model. Neuroscience 28(1), 233-244 (1989).

71 Alder J, Fujioka W, Lifshitz J, Crockett DP, Thakker-Varia S. Lateral fluid percussion: model of traumatic brain injury in mice. J. Vis. Exp. (54), pii: 3063 (2011).

72 Qin Y, Li GL, Xu XH, Sun ZY, Gu JW, Gao FB. Brain structure alterations and cognitive impairment following repetitive mild head impact: An in vivo MRI and behavioral study in rat. Behav. Brain Res. doi:10.1016/j.bbr.2016.08.008 (2016) (Epub ahead of print).

73 Mcateer KM, Corrigan F, Thornton E, Turner RJ, Vink R. Short and long term behavioral and pathological changes in a novel rodent model of repetitive mild traumatic brain injury. PLoS ONE 11(8), e0160220 (2016).

74 Briggs DI, Angoa-Perez M, Kuhn DM. Prolonged repetitive head trauma induces a singular chronic traumatic encephalopathy-like pathology in white matter despite transient behavioral abnormalities. Am. J. Pathol. 186(11), 2869-2886 (2016).

75 Augustinack JC, Schneider A, Mandelkow EM, Hyman BT. Specific tau phosphorylation sites correlate with severity of neuronal cytopathology in Alzheimer's disease. Acta Neuropathol. 103(1), 26-35 (2002).

76 Nichols JN, Deshane AS, Niedzielko TL, Smith CD, Floyd CL. Greater neurobehavioral deficits occur in adult mice after repeated, as compared with single, mild traumatic brain injury (mTBI). Behav. Brain Res. 298(Pt B), 111-124 (2016).

77 Xiao-Sheng H, Sheng-Yu Y, Xiang Z, Zhou F, Jian-Ning Z. Diffuse axonal injury due to lateral head rotation in a rat model. J. Neurosurg. 93(4), 626-633 (2000).

78 Gutierrez E, Huang Y, Haglid K et al. A new model for diffuse brain injury by rotational acceleration: I model, gross appearance, and astrocytosis. J. Neurotrauma 18(3), 247-257 (2001).

79 Browne KD, Chen XH, Meaney DF, Smith DH. Mild traumatic brain injury and diffuse axonal injury in swine. J. Neurotrauma 28(9), 1747-1755 (2011).

80 Gennarelli TA, Thibault LE, Adams JH, Graham DI, Thompson CJ, Marcincin RP. Diffuse axonal injury and traumatic coma in the primate. Ann. Neurol. 12(6), 564-574 (1982).

81 Blennow K, Hardy J, Zetterberg H. The neuropathology and neurobiology of traumatic brain injury. Neuron 76(5), 886-899 (2012).

82 Cloots RJ, Gervaise HM, Van Dommelen JA, Geers MG. Biomechanics of traumatic brain injury: influences of the morphologic heterogeneities of the cerebral cortex. Ann. Biomed. Eng. 36(7), 1203-1215 (2008).

83 Ho J, Kleiven S. Can sulci protect the brain from traumatic injury? J. Biomech. 42(13), 2074-2080 (2009).

84 Omalu B, Bailes J, Hamilton RL et al. Emerging histomorphologic phenotypes of chronic traumatic encephalopathy in American athletes. Neurosurgery 69(1), 173-183; discussion 183 (2011). 